\title{
Cost-Effectiveness of Interventions for Alternate Food to Address Agricultural Catastrophes Globally
}

\author{
David C. Denkenberger ${ }^{1,2} \cdot$ Joshua M. Pearce ${ }^{3,4}$
}

Published online: 21 September 2016

(c) The Author(s) 2016. This article is published with open access at Springerlink.com

\begin{abstract}
The literature suggests there is about a $1 \%$ risk per year of a $10 \%$ global agricultural shortfall due to catastrophes such as a large volcanic eruption, a medium asteroid or comet impact, regional nuclear war, abrupt climate change, and extreme weather causing multiple breadbasket failures. This shortfall has an expected mortality of about 500 million people. To prevent such mass starvation, alternate foods can be deployed that utilize stored biomass. This study developed a model with literature values for variables and, where no values existed, used large error bounds to recognize uncertainty. Then Monte Carlo analysis was performed on three interventions: planning, research, and development. The results show that even the upper bound of USD 400 per life saved by these interventions is far lower than what is typically paid to save a life in a less-developed country. Furthermore, every day of delay on the implementation of these interventions costs 100-40,000 expected lives (number of lives saved multiplied by the probability that alternate foods would be required). These interventions plus training would save 1-300 million expected lives. In general, these
\end{abstract}

David C. Denkenberger

david.denkenberger@colorado.edu;

http://gcrinstitute.org/

1 Global Catastrophic Risk Institute, Calabasas, CA 91302, USA

2 Department of Civil and Architectural Engineering, Tennessee State University, Nashville, TN 37209, USA

3 Department of Materials Science and Engineering, Michigan Technological University, Houghton, MI 49931, USA

4 Department of Electrical and Computer Engineering, Michigan Technological University, Houghton, MI 49931, USA solutions would reduce the possibility of civilization collapse, could assist in providing food outside of catastrophic situations, and would result in billions of dollars per year of return.

Keywords Agricultural catastrophe - Alternate food - Global catastrophic risk - Intervention costeffectiveness

\section{Introduction}

A number of catastrophic events could cause a roughly $10 \%$ global agricultural shortfall, including a medium-sized asteroid/comet impact (Napier 2008), a large but not super volcanic eruption, full-scale nuclear war if the impacts are less than anticipated (Turco et al. 1990), regional nuclear war (for example, India-Pakistan (Özdoğan et al. 2013)), abrupt regional climate change (Valdes 2011), complete global loss of bees as pollinators (Aizen et al. 2009), a super crop pest or pathogen, and coincident extreme weather, resulting in multiple breadbasket failures (Bailey et al. 2015). Other events would not directly affect food production, but still could have similar impacts on human nutrition. Some of these include a conventional world war or pandemic that disrupts global food trade, and the resultant famine caused in food-importing countries (Keller 1992; Waldman 2001; Goodhand 2003). Other issues that do not affect food production directly include overreaction to oil prices, phosphorus prices, nitrogen prices, desertification, salinization, erosion, depletion of aquifers, and slow climate change (Ehrlich and Ehrlich 2013). These all could occur with concomitant price speculation, pricing the global poor out of food.

Generally, the technical solution for feeding everyone in these scenarios would be to (1) increase cultivated area; (2) 
reduce the amount of preharvest losses (for example, from pests and weeds) (Oerke 2006); (3) reduce yield underachievement (for example, because of insufficient fertilizers and not optimal plant varieties) (Foley et al. 2011); (4) reduce food wasted in the process of distribution (Godfray et al. 2010) and at the household level; and (5) reduce the use of edible food for the production of biofuels and feed for livestock and pets (Denkenberger and Pearce 2015). Another solution to these problems is storing more food, but this would be expensive and cannot be done rapidly without exacerbating hunger among the world's destitute people (Baum et al. 2015). Thus, conventional approaches to a $10 \%$ global agricultural shortfall would not be adequate to stop an escalation in current hunger-related disease and death (UNICEF 2006).

Recently, 10 alternative food solutions that do not involve conventional agriculture have been proposed for global catastrophes (Denkenberger and Pearce 2014). Here the solutions that would likely be the most relevant in the event of a $10 \%$ agricultural shortfall are discussed (Table 1). One solution for an alternate is substituting for human edible animal feed using the commercially demonstrated technology that converts stranded (remote from markets) natural gas to animal feed using bacteria (Unibio 2014). Many other solutions involve converting agriculture and logging residues to food/feed. For cellulose digesters, such as cattle, sheep, and goats, as well as horses kept as pets, the practice of feeding excrement from other animals could be expanded. With this high-nitrogen food source, lower-nitrogen sources could be used in addition, such as agricultural residues that are not green and tree leaves that have been depleted of their nutrients and shed. For noncellulose digesting animals such as pigs, turkeys, and chickens, as well as cats and dogs kept as pets, discarded food waste can be used more extensively; this is a new solution that was not very relevant for the $100 \%$ agricultural shortfall studied previously (Denkenberger and Pearce 2014). Although much of the current food waste is appropriate for human consumption, even food that is regarded as spoiled by human standards could be acceptable for animals (Henneberg 1998).
The difficulty of providing solutions is reduced for such a relatively small percentage of agricultural shortfall. Ideally, solutions would require minimum lifestyle changes for everyone. A way of doing this is finding alternate feed sources for livestock and pets. Grains make up about half of global calorie production (Meadows et al. 2004) and livestock consume $35 \%$ of the world's grain (Earth Policy Institute 2011). Therefore, if grains were completely replaced with alternate feed sources in animal diets, this could make up for an $18 \%$ global agricultural shortfall and would be more than sufficient for a $10 \%$ global agricultural shortfall. This solution, however, does not even account for the possibility of substituting non-grain edible food used as animal feed (though animal only-feed such as grass could be impacted by the catastrophe).

Another range of options enables direct human food production from tree-related biomass, such as extracting sustenance from leaves (for example, pine needle tea) (Kim and Chung 2000), and mushrooms growing on woody residues. The waste from this process can be fed to cellulose digesting animals (Spinosa 2008). Another alternative direct mechanism for providing human food from conventionally non-food sources is utilizing current cellulosic biofuel techniques. For example, enzymes could be used on agricultural residues to create human edible sugars (Langan et al. 2011). With the reclamation of nutrients from excrement and food waste and the possible injection of new nutrients into the food system from leaf litter, for example, the need for artificial fertilizer would fall. This would enable macronutrient (for example, nitrogen) fertilization of part of the ocean, which could allow significant ramping of fish harvesting (Denkenberger and Pearce 2015). Many of these alternate food sources may be valuable even outside a catastrophe for reducing the world's current undersupply of food (FAO 2015) to the poorest people (Gwatkin 1980).

A $10 \%$ global agricultural shortfall would roughly triple the price of grain (Bailey et al. 2015), which would be expected to aggressively exacerbate global food insecurity. Many of these alternate food solutions, if ramped up

Table 1 Human food sources and the alternate feedstock inputs for these foods

\begin{tabular}{ll}
\hline Food animals/pets & Feedstock \\
\hline Cattle, sheep, goats, horses & $\begin{array}{c}\text { Natural gas digesting bacteria, excrement, leaf litter, agricultural } \\
\text { residues, wood residue from growing mushrooms }\end{array}$ \\
Pigs, turkeys, chickens, cats, and dogs & Food discarded by humans, natural gas digesting bacteria \\
Leaf tea & Green leaves and agricultural residues \\
Mushrooms & Woody residues \\
Sugar produced by enzymes & Leaf litter, agricultural residues \\
Fish & Algae grown because of ocean fertilization \\
\hline
\end{tabular}


quickly to cover a $100 \%$ agricultural shortfall individually, could be much more expensive than the new high grain price. However, in a $10 \%$ agricultural shortfall, each food source would only have to provide a relatively small amount of food. Therefore, less extreme measures would have to be taken, lowering the cost. These costs, however, have not been quantified. Neither has the cost of each of the alternative foods been quantified as a function of preparation and planning, research and development, and training.

In order to overcome this knowledge gap and provide planners with better cost estimates on various alternative food interventions, an analysis was performed here with a numerical model to estimate the cost-effectiveness of (1) planning at the international level; (2) investing in research including experiments to prove the concepts; (3) the development of the technologies to demonstrate scalability; and (4) the training of professionals and citizens. For each of the four interventions, five cost-effectiveness measures were calculated: cost per life saved, benefit to cost ratio, net present value, payback time, and internal rate of return. The results are discussed and conclusions are drawn about the cost-effectiveness of food security preparations for global catastrophes.

\section{Materials and Methods}

This study developed a model (Fig. 1) using three inputs: (1) the probability of a $10 \%$ agricultural shortfall per year;

(2) the lives lost due to this $10 \%$ agricultural shortfall without alternative foods; and (3) the statistical value of a

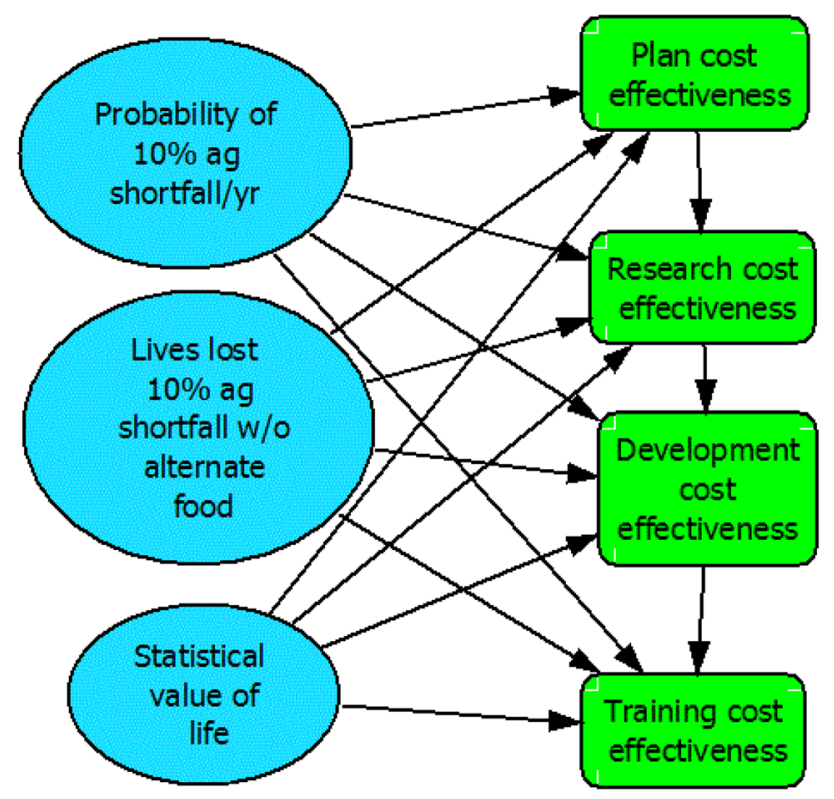

Fig. 1 Model overview life. These three inputs were used in quantitative analysis software to determine the cost-effectiveness of planning, research, development, and training. To determine each model parameter, the available literature was surveyed to estimate the model parameters. In many cases this is straightforward and there is a high degree of confidence in those inputs. However, in cases where no literature values were available or the confidence was low in those values, logic is employed with large error bounds to recognize the uncertainty. Based on the confidence of a parameter an appropriate probability distribution was chosen for the parameter.

\subsection{Modeling Environment}

The modeling was implemented in Analytica 4.5. Combining the uncertainties in all the inputs was performed with a Median Latin Hypercube ${ }^{1}$ analysis with the maximum uncertainty sample of 32,000 (run time on a personal computer was seconds). The assumption is that all the uncertainties are independent except where noted.

In addition to identifying the input variables whose uncertainties most affect the outputs, an importance analysis was performed using Analytica. This analysis uses the absolute rank-order correlation between each input and the output as an indication of the strength of monotonic relations between each uncertain input and a selected output, both linear and otherwise (Morgan and Henrion 1990; Chrisman et al. 2007).

\subsection{Explanation of Credible Intervals}

A confidence interval is typically used when there are data for the likelihood of events. However, since most of the events considered here have not occurred, the Bayesian credible interval is used (Bolstad 2013). Table 2 summarizes the credible intervals for all the input variables. The upper and lower bounds for the probabilities of success of the alternative food interventions should not be viewed as hard limits, but rather as a logical progression towards greater credible intervals of the probabilities of success with aggregate of no preparation $<$ planning $<$ planning + research $<$ planning + research + development $<$ planning + research + development + training.

\subsection{Catastrophe Probability Distributions}

There are three types of probability distributions used in this study: (1) log-normal; (2) beta; and (3) gamma. Lognormal distributions are used for a continuous probability

\footnotetext{
${ }^{1}$ Similar to Monte Carlo, but better performing (Keramat and Kielbasa 1997).
} 
Table 2 Credible intervals for all the input variables

\begin{tabular}{|c|c|c|}
\hline Variable & Distribution type & 2.5-97.5 percentile \\
\hline Probability per year of a $10 \%$ global agricultural shortfall & Lognormal & $0.3-3 \%$ \\
\hline Number of fatalities due to a $10 \%$ agricultural shortfall (millions) & Gamma & $20-2000$ \\
\hline Chance of alternate foods working as planned with current preparation & Lognormal & $0.1-1 \%$ \\
\hline Chance of alternate foods working with a plan & Lognormal & $1-10 \%$ \\
\hline Cost of plan ( $\$$ million $)$ & Lognormal & $1-30$ \\
\hline Plan horizon of effectiveness (years) & Lognormal & $3-30$ \\
\hline Chance of alternate foods working with plan and research & Lognormal & $3-30 \%$ \\
\hline Cost of research ( $\$$ million) & Lognormal & $10-100$ \\
\hline Research horizon of effectiveness (years) & Lognormal & $6-60$ \\
\hline Chance of alternate foods working with plan, research, and development & Lognormal & $7-70 \%$ \\
\hline Cost of development ( $\$$ million) & Lognormal & $10-100$ \\
\hline Development horizon of effectiveness (years) & Lognormal & $6-60$ \\
\hline Chance of alternate foods working with plan, research, development, and training & Beta & $9-90 \%$ \\
\hline Cost of training ( $\$$ million) & Lognormal & $10,000-100,000$ \\
\hline Training horizon of effectiveness (years) & Not applicable & 10 \\
\hline Value of statistical life ( $\$$ million) & Lognormal & $0.003-3$ \\
\hline
\end{tabular}

distribution of a random variable whose logarithm is distributed according to the normal distribution. The beta distribution is a continuous probability distribution defined on the interval $[0,1]$ (though this can be modified), which is parameterized by two positive shape parameters that appear as exponents of the random variable and control the shape of the distribution to model the behavior of random variables limited to intervals of finite length. The gamma distribution is a two-parameter family of continuous probability distributions used for cases with a large range of values as it is a maximum entropy probability distribution for a random variable. The types of distributions used for the variables in this analysis are summarized in Table 2. Most of the distributions are lognormal, but this was inadequate to produce reasonable behavior for two of the variables. The overall conclusions are not very sensitive to the choice of distribution type.

\subsection{Probabilities}

The following sections explain the rationale of the distribution types and parameters for the variables in the model.

\subsubsection{Probability of a $10 \%$ Global Agricultural Shortfall}

A $95 \%$ confidence interval for the probability of a $10 \%$ global agricultural shortfall is estimated to be log-normally distributed between $0.3 \%$ per year and $3 \%$ per year. The lower limit corresponds to the sum of several fairly wellquantified risks. The probability of a volcano eruption like the one of Mount Tambora, Indonesia in 1815 (volcanic explosivity index $=7$ ), which caused "the year without a summer" and famines in 1816 is about $0.1 \%$ per year (Mason et al. 2004). The probability of accidental full-scale nuclear war is roughly $0.2 \%$ per year $^{2}$ (Barrett et al. 2013). This would likely cause at least a $10 \%$ global agricultural shortfall, and probably a much higher shortfall (Turco et al. 1990). The probability of natural abrupt regional climate change of roughly $10{ }^{\circ} \mathrm{C}$ decrease in one decade is $0.01 \%$ per year, and an order of magnitude increase in this probability due to anthropogenic emissions has been estimated (Denkenberger and Pearce 2014). One estimate of the probability of extreme weather causing a $10 \%$ agricultural shortfall is now about $1 \%$ per year (Bailey et al. 2015). The Bailey et al. study found that this risk is increasing, and if the other nonquantified risks are significant, the actual risk could be $3 \%$ per year or more.

\subsubsection{Uncertainty in the Number of Fatalities Due to a $10 \%$ Agricultural Shortfall}

The uncertainty in the number of fatalities due to a $10 \%$ agricultural shortfall is very large. On the optimistic extreme, there could be aggressive government support or charity such that the vast majority of the global poor could generally afford sufficient food. If the crisis were only a year or two, loans could be feasible, either to poor individuals or poor countries. The necessary conservation (less waste, less food to animals, and so on) in the developed

\footnotetext{
2 This is found by taking the mean of a lognormal distribution from $0.01 \%$ per year to $1 \%$ per year.
} 
countries could be achieved by higher prices or rationing. However, even if mass starvation is averted, generally there would be more malnutrition and increasing susceptibility to disease. The poor would be less able to afford other lifesaving measures, and a pandemic would be more likely. Even if food aid is available, it may not be possible to get the food to the people who need it. Therefore, near zero mortality is unlikely. At the same time, even with no catastrophe, 6.5 million people die of hunger-related diseases per year (UNICEF 2006). On the other extreme, there could be food export restrictions or bans, as implemented by India, Vietnam, Egypt, and China in 2008 (Helfand 2013) when the situation was much less serious. This hoarding on a country level could also be coupled with hoarding on an individual level. This could dramatically reduce the food supply available to poor people.

Armed conflict could be in some countries' best interest, which could also aggravate famine (Keller 1992; Waldman 2001; Goodhand 2003). These wars could even evolve into nuclear conflict, which would further impact food supplies. One estimate of the number of people at risk of starvation due to regional nuclear conflict is 2 billion (Helfand 2013). To capture this very large variation in behavior, a gamma function was used with a $95 \%$ credible interval of about 20 million to 2 billion fatalities, with a median of 400 million. ${ }^{3}$ Figure 2 shows cumulative probability, so the vertical axis values of 0.025 and 0.975 bound the range. There are currently 870 million people who are chronically malnourished (Helfand 2013). These people could quickly starve if there were a significant price increase (urban) or a significant reduction in farm output (rural). However, once 400 million people have starved to death ( $6 \%$ of the current global total population), this would free up significant food for the remaining people. Therefore, 400 million people starving to death is used as the median (vertical axis value of 0.5 in Fig. 2). This distribution also includes the uncertainty in the duration of the shortfall which would run from 1 year for extreme weather to more than 10 years for nuclear war (Özdoğan et al. 2013). The uncertainty also captures the variation in the scope of the shortfall-it could be fairly uniform globally or concentrated in either developed or developing countries. If there are large regional imbalances, shipping would be adequate technically (Denkenberger and Pearce 2014), but there would be economic and political difficulties.

\subsubsection{Lives Saved and the Statistical Value of a Life}

To calculate the lives saved, the expected lives saved in the first year are multiplied by the time horizon. This is because future lives saved are typically not discounted, and

\footnotetext{
${ }^{3}$ Gamma function parameters: alpha $=1.1$, beta $=1$ billion, maximum $=7$ billion.
}

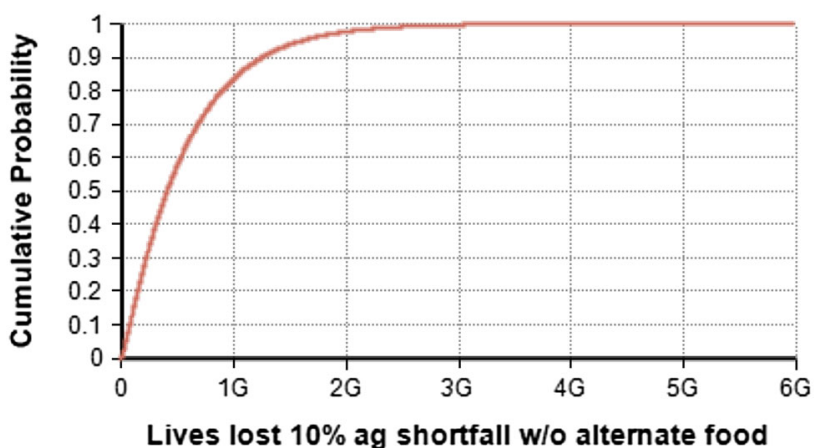

Fig. 2 Cumulative probability of lives lost given a $10 \%$ agricultural shortfall and no alternate food ( $\mathrm{G}$ is billion)

the number of lives saved per year would likely increase because of population growth. With an expected total lives saved and cost of plan, the cost per life saved is calculated.

Most of the people who would die in an agricultural catastrophe would currently be living in global poverty. The most effective interventions can save these people's lives now for only about USD 3000 per life (GiveWell 2015b). This is the cost to save a life, not necessarily the value of a statistical life. However, many people believe all people should be valued equally, and closer to the developed country valuation of USD 1-10 million per statistical life (Robinson 2007). This is questionable operationally because the global poor may prefer money to be spent on their own consumerism (for example, for food now), rather than reducing risks to lower levels.

However, there will likely be some fatalities even in developed countries. Because of the higher price of food, people would be more willing to eat spoiled food and in food scarcity-aggravated conflict scenarios, many rich people could die. Therefore, an attempt was made to bridge these perspectives with a lognormal distribution with a $95 \%$ credible interval ranging from about USD 3000-USD 3 million per life. This has a median value of approximately USD 100,000 per life. One global compilation of values of statistical lives (VSLs) indicated that the VSL was roughly 100 to 200 times the gross domestic product (GDP) per capita (Miller 2000). This study found a global average VSL of USD 650,000 . If the people were in dollara-day poverty, this would imply roughly USD 50,000 for the VSL. Since not all of the people who die in a catastrophe would be in dollar-a-day poverty, the USD 100,000 median VSL considered here is roughly consistent with Miller (2000). Thus, for those who view lives as being worth more, this analysis is conservative.

This allows the model to find a benefit to cost ratio; the model conservatively ignores benefits other than lives saved, such as lower food prices for people who would have survived anyway. The total benefit minus the cost yields the net present value (NPV). The payback time is the number of years after the project has been completed for 


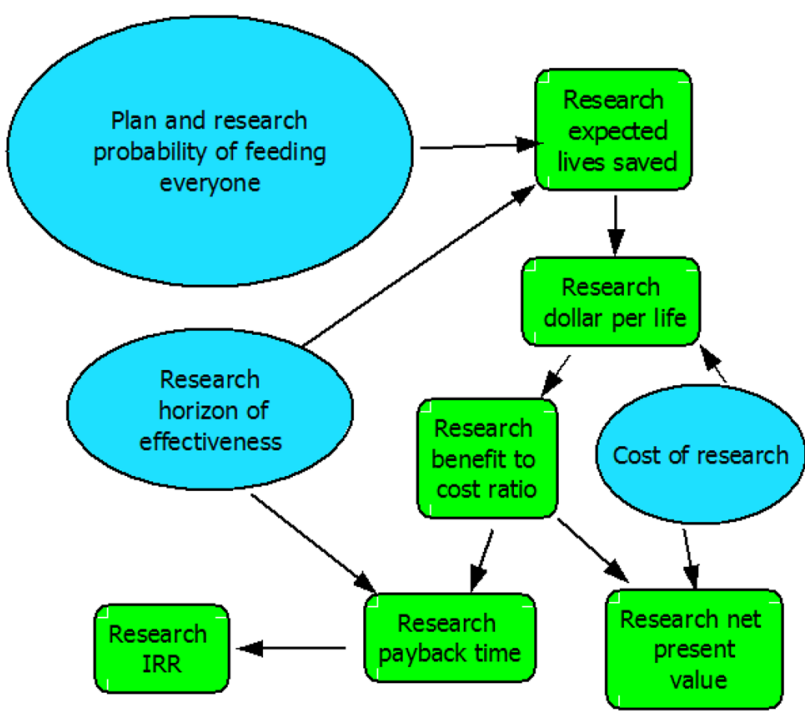

Fig. 3 Research cost-effectiveness module

the expected benefit to pay back the cost. Since the payback times are short, a good approximation of the internal rate of return (IRR) is the reciprocal of the payback time (Pearce et al. 2009).

\subsection{Cost-Effectiveness}

Figure 3 shows the functionality within the research costeffectiveness module. The other cost-effective modules are organized similarly. Though alternate foods may not prevent all the fatalities in a given scenario, the probability of alternate foods solving the problem could be thought of as a larger probability only partially solving the problem.

\subsubsection{Planning}

With global cooperation (for example, sharing information and trading food), it was estimated that these alternate food solutions could feed everyone even without preparation (Denkenberger and Pearce 2014). There is evidence in the literature that humans are capable of such noble behavior in a local crisis (for example, the famine in Ethiopia in 1984-1985) (Von Braun et al. 1999). However, this assumption may be overly optimistic given counter examples such as the Bengal, India famine in 1943 that was much worse than the food supply shortfall (Lazzaro 2013). Knowledge that everyone could be saved would facilitate global cooperation, but still relatively few people know about the solutions.

The equivalent probability that alternate foods would prevent everyone from starving with current preparation is quite uncertain. At least 700,000 people have heard about the concept based on impression counters for the roughly 10 articles, podcasts, and presentations for which there were data including Science (Rosen 2016) (out of more than 100 media instances). It is also possible that, if there is some warning before a catastrophe, people knowledgeable about alternate foods could use the intense media interest to inform the general public (including policymakers). It is possible that given a catastrophe, people will independently invent these solutions. Because of this, a lognormal probability distribution is assumed with a $95 \%$ credible interval of $0.1-1 \%$ chance of alternate foods working as planned with current preparation.

If there were an international plan for how efforts could be coordinated to ramp up alternate foods given a catastrophe, the probability of success is expected to increase significantly. This is especially true because a plan could start to be implemented if there is warning before a catastrophe. A lognormal distribution is assumed with a $95 \%$ credible interval of 1 to $10 \%$ chance of feeding everyone with alternate foods in this case. There is overlap between this distribution and the probability distribution of alternate foods working with current preparation. It is not reasonable that the addition of the plan would increase the probability of success less than $1 \%$, so it is truncated at $1 \%$.

The cost of the plan is assumed to be lognormally distributed and have a $95 \%$ credible interval of USD 1 million-USD 30 million. The lower values correspond to a few person years of planning plus briefing the relevant individuals. The higher values would involve more continuous briefing and updating and allow for cost overruns. The time horizon of the effectiveness of the plan is assumed to be lognormally distributed and have a $95 \%$ credible interval of 3-30 years. Lower values are similar to a presidential term, while higher values indicate more maintenance. The probability of success, cost, and time horizon of the plan are assumed to be independent, which produces larger variances than reality, which is conservative with respect to the unfavorable bound of costeffectiveness.

\subsubsection{Research}

If targeted experiments and modeling of alternate foods were performed, the probability of success would increase significantly as this is the primary uncertainty in alternative food proposals. A lognormal distribution with a $95 \%$ credible interval of 3-30\% chance of feeding everyone with alternate foods is assumed with both a plan and experiments. The improvement is truncated at $1 \%$.

It is assumed that the cost of the research is lognormally distributed and has a $95 \%$ credible interval of USD 10 
million-USD 100 million. 445 tree species made up $76 \%$ of the growing stock in 88 countries (FAO 2005). ${ }^{4}$ It was found that 100 tree species for half the global growing stock is a reasonable order of magnitude estimate. However, even simply testing on one hardwood and one softwood could have significant explanatory value because of the significant differences in constituent compounds. For solutions involving nonwoody biomass (for example, leaf tea and enzyme-produced food), fewer species would likely be required for a given fraction of biomass coverage. This is because of the large fraction of nonwoody biomass that are crops, and the domination of rice, maize, and wheat among crops. ${ }^{5}$ For the fishing solution, relatively few feedstock organisms (for example, algae) may need to be investigated. For methane-digesting bacteria, only a few different natural gas compositions may need to be tested. There is also the issue of how many food organisms would need to be tested. In the case of currently domesticated animals like chicken and cattle, it would be relatively few. However, it could be significantly more for other categories like mushrooms. Other experiments include growing photosynthetic crops in the crisis conditions of the tropics (cold and high ultraviolet radiation), biomass supply experiments, and human nutrition experiments. It would be valuable to synthesize existing experiments for relevant insights. Further modeling of other issues such as energy and water would be important.

The order of magnitude cost of a graduate student year in the United States with some experimental facilities and overhead is USD 100,000. A scientific paper can be produced in roughly 3 years when running a targeted experiment like one organism consuming one feedstock type. Therefore, the lower bound roughly corresponds to 30 such studies. This would involve significant extrapolation to other species. However, the upper bound would allow about 300 studies, producing higher confidence. The brute force method of testing hundreds of feedstock species with many food species could cost billions of dollars. Using a designed experiment approach the number of experiments could be greatly reduced while yielding the majority of the explanatory value (Myers et al. 2009). Research is generally longer-lived than planning, so the time horizon of the

\footnotetext{
${ }^{4}$ This statistic represented the 10 most common tree species in each country. Therefore, there is some overlap of the most common species across countries. The three most common species in each country collectively covered $56 \%$ of the total growing stock. If linearly extrapolated, this would imply 130 tree species for roughly half the global growing stock. In reality, the fact that there are more countries would increase the number of species. However, even though one species was the third most common in a small country, it might not be common globally. Therefore, this could reduce the number of species required globally for half the growing stock.

5 Rice, maize, and wheat provide about $60 \%$ of the world's food energy (Loftas and Ross 1995).
}

effectiveness of the plan is estimated to be lognormally distributed and have a $95 \%$ credible interval of 6 to 60 years.

\subsubsection{Development}

If in addition to planning and research, development of alternate foods outside the laboratory were achieved, the probability of success would increase further. A lognormal distribution is assumed with a $95 \%$ credible interval of $7-70 \%$ chance of feeding everyone with alternate foods with a plan, research, and development approach. The improvement is truncated at $1 \%$.

The cost of the development is assumed to be lognormally distributed and has a $95 \%$ credible interval of USD 10 million-USD 100 million, the same as for research. This is because even though moving to a scale of production outside the laboratory is more expensive for a particular scenario, only the most promising scenarios would be chosen. The lower values correspond to choosing the most promising food and feedstock organisms and extrapolating to other organisms. The higher values would involve more organisms. This development would also facilitate the estimation of costs given mass production. The same time horizon is used as for research.

\subsubsection{Training}

If in addition to planning, research, and development, catastrophe training were continuously implemented, this would further increase the probability of success. Three low-cost training options are described here. First, audio and video training modules could be distributed by the media after the catastrophe. Second, lower levels of government could be trained how to respond and to train others. Third, public service announcements before the catastrophe would ensure that nearly everyone knows about the alternate food solutions and therefore will be more likely to stay calm if a catastrophe occurs (this could even be done as part of the planning intervention). More expensive approaches would be training engineers and technicians how to retrofit industrial processes for alternate food production. Farmers could be trained on alternate food production (for example, with school curricula).

If training involved $3 \%$ of the global population, and the sum of the cost and opportunity cost of the training were USD 10 per hour, and it were $5 \mathrm{~h}$ per year, this is roughly USD 10 billion per year. The lower bound could be training $0.3 \%$ of the global population similarly. The lowcost options could be significantly less expensive than this, but it is assumed that the training package is generally larger than the other interventions. More money than the upper bound could be spent to train the majority of citizens. 
However, because of food storage, it is not critical that alternate food production begin immediately and it is assumed that the media can be restored quickly (if the catastrophe even disrupts media services in the first place) to disseminate the message. If direct apprenticeship is required, as long as this is of short duration, such as weeks, it could quickly spread exponentially through the population. Therefore, there will be diminishing returns for additional training before the catastrophe. A beta distribution (to avoid truncation) is assumed with a $95 \%$ credible interval of 9-90\% chance of feeding everyone with alternate foods with a plan, research, development, and training. ${ }^{6}$ The improvement is truncated at $1 \%$. The cost of the training is assumed to be lognormally distributed and has a $95 \%$ credible interval of USD 10 billion-USD 100 billion. In this case, it is assumed that the training is over a specific period of 10 years.

\section{Results and Discussion}

The credible intervals are increased as multiple variables are combined. This means that the reliability of the final result is the same as the reliability of the input intervals. Table 3 shows the $95 \%$ credible interval for the five costeffectiveness measures for each of the four interventions. The 2.5 percentile row has all the lower values in the distribution, and the 97.5 percentile row has the higher values. Sometimes low values indicate high cost-effectiveness, and sometimes they indicate low cost-effectiveness, so there is not a consistent scenario across the row. For the plan, research, and development, even the upper bound of USD 400 per life saved is significantly lower than the minimum that is paid to save a life in global poverty. Many of these alternative food interventions are able to provide greater food security to the world's most destitute now. The value of these lives saved (which could amount to over 17,000 lives/day) was not factored into the calculations here, making all of these calculations exceptionally conservative. With the very high benefit to cost ratio, only investing millions of dollars yields billions or even trillions of dollars of benefits. The strikingly short time to pay back the investment once the project is completed demonstrates the urgency of completing these projects. In reality, to maximize benefit, it would make sense to spend more money to accelerate the project, including having interim deliverables.

Full-scale training is significantly less cost-effective because it is so much more expensive than the other options. Still, the median cost per life saved is USD 6000, which is similar to the best global poverty interventions

\footnotetext{
${ }^{6}$ Beta parameters: $X=2, Y=2$, minimum $=0$, maximum $=1$.
}

such as mosquito bed nets for malaria prevention (GiveWell 2015a). Therefore, it is likely beneficial to implement at least some training activities. The opportunity cost of not implementing these interventions was estimated. The probability of feeding everyone given no interventions was subtracted from the probability of success given all four interventions, truncated at an improvement of $4 \%$ (the sum of the individual minimum improvements). The result was that every day delay of the implementation of these interventions costs 10 to 40,000 expected lives. Overall, the four interventions taken together would save between 1 million and 300 million lives.

For the costs per life saved, the mortality of the catastrophe without alternate foods was the most important input variable by a significant margin. However, the other cost-effectiveness metrics depended on the statistical value of life, while the costs per life saved do not. For these other cost-effectiveness metrics, the most important variable was the statistical value of life. For this sensitivity analysis, the mortality of the catastrophe without alternate foods is made into an independently sampled probabilistic parameter, with values of 20 million, 200 million, and 2 billion. Similarly, the values used for the statistical value of life are USD 1000, USD 30,000, and USD 1 million. Besides the statistical value of life not affecting the cost per life saved, these variations affect all 20 cost-effective measures in the same way. The NPV value of the plan is chosen to illustrate the effect in Table 4. When the mortality is being varied, the statistical value of life retains its regular distribution. Similarly, when the statistical value of life is being varied, the mortality retains its regular distribution. The variation in NPV due to these sensitivity studies is smaller than the variation in cost per life saved due to the independent variation of all the input variables. Therefore, the distributions shown in Table 3 can be thought of as a form of sensitivity analysis.

The planning and research can be done in parallel. The development should be done after the research in order to focus on the feed organisms that are most promising. The expected mean cost-effectiveness of training is still good, and this could be done in parallel with development. Seen as a program, the first year could be a few tens of millions of dollars to plan and research. Then successive years could be billions of dollars per year, mostly for training, but a little for development.

These solutions would reduce the possibility of civilization collapse. If civilization collapsed, it is not guaranteed that it would recover, so it could affect many future generations (Beckstead 2013). These considerations further demonstrate how conservative the analysis is. These solutions could also protect biodiversity (Baum et al. 2016). If there were mass starvation, not only would few humans care about protecting other species from the impacts of the 
Table $395 \%$ credible interval for the five cost-effectiveness measures for each of the four interventions

\begin{tabular}{|c|c|c|c|c|c|c|}
\hline Intervention & $\begin{array}{l}\text { Cost effectiveness } \\
\text { measure }\end{array}$ & $\begin{array}{l}\text { Cost per life } \\
\text { saved (\$) }\end{array}$ & $\begin{array}{l}\text { Benefit to } \\
\text { cost ratio }\end{array}$ & $\begin{array}{l}\text { NPV (\$ } \\
\text { billion) }\end{array}$ & $\begin{array}{l}\text { Payback } \\
\text { time (years) }\end{array}$ & $\begin{array}{l}\text { Internal rate } \\
\text { of return } \\
\text { (\%/year) }\end{array}$ \\
\hline \multirow[t]{2}{*}{ Plan } & 2.5 percentile & 0.3 & 30 & 0.2 & $0.00,002$ & 400 \\
\hline & 97.5 percentile & 300 & 500,000 & 2000 & 0.3 & 5000,000 \\
\hline \multirow[t]{2}{*}{ Research } & 2.5 percentile & 0.3 & 20 & 0.8 & $0.00,006$ & 100 \\
\hline & 97.5 percentile & 400 & 400,000 & 10,000 & 0.7 & 2000,000 \\
\hline \multirow[t]{2}{*}{ Development } & 2.5 percentile & 0.2 & 20 & 0.8 & $0.00,003$ & 100 \\
\hline & 97.5 percentile & 400 & 700,000 & 20,000 & 0.7 & 3000,000 \\
\hline \multirow[t]{2}{*}{ Training } & 2.5 percentile & 200 & 0.02 & -60 & 0.02 & 0.2 \\
\hline & 97.5 percentile & 700,000 & 500 & 10,000 & 600 & 5000 \\
\hline
\end{tabular}

Table 4 Plan cost per life saved sensitivity with respect to mortality and VSL

\begin{tabular}{lrlr}
\hline Mortality of catastrophe & Plan NPV (\$ billion) & Value of statistical life & Plan NPV (\$ billion) \\
\hline 20 million & 20 & $\$ 1000$ & 2 \\
200 million & 200 & $\$ 30,000$ & 70 \\
2 billion & 2000 & $\$ 1$ million & 2000 \\
\hline
\end{tabular}

catastrophe, but humans would actively eat some species to extinction. Clearing land to expand conventional agriculture would negatively affect biodiversity. Therefore, alternate foods, by reducing the chance of mass starvation, would have important environmental benefits.

There are also catastrophes that could cause order of magnitude $100 \%$ agricultural shortfall for years, such as a large asteroid/comet impact (Napier 2008), a super volcanic eruption (Rampino 2008), and nuclear winter. These are generally lower probability events. Globally there is less than 1 year of food storage (Do et al. 2010), so alternate food would be required to feed everyone. The economics of interventions in this case have been analyzed for the United States, but future work is needed to analyze the economics of interventions for this case globally. Since many of the interventions for the order of magnitude $10 \%$ agricultural shortfalls would ameliorate the order of magnitude $100 \%$ agricultural shortfalls, this further underscores the conservatism of the cost-effectiveness of these interventions. Additional work is also needed to quantify the value of developing alternative food approaches now to help reduce mortality from hunger and hunger-related diseases in the present.

The limitations of this study were primarily the lack of data that resulted in sometimes large ranges in the variables. Future work is needed to better focus the analysis and to reduce the uncertainties. For example, experiments on a few of the alternative foods could provide more robust values of study duration, which would provide a tighter range on the costs of research.

\section{Conclusion}

There is approximately $1 \%$ risk per year of a $10 \%$ global agricultural shortfall. This has a mean expected mortality of 500 million people given this shortfall. Alternate foods, which exploit fossil fuels or stored biomass as a feedstock, could save everyone from starving in such a catastrophe. However, current awareness is low and the technologies need to be better developed to provide this insurance. Three interventions costing in the tens of millions of dollars are planning, research, and development. The results of this study show that even the upper bound of USD 400 per life saved by these interventions is far lower than what is typically currently paid to save a life in a less-developed country. The lower bound of these interventions is about USD 0.30 per life saved. Every day delay on the implementation of these interventions costs 100-40,000 expected lives. Overall, the four interventions taken together would save between 1 million and 300 million expected lives (lives saved in the event of a $10 \%$ global agricultural shortfall multiplied by the probability of the catastrophe). In general, these solutions would also reduce the probability of civilization collapse and help protect biodiversity. 
Acknowledgments Anthony Barrett, Steven Greidinger, Carl Shulman, and Seth Baum contributed helpful discussions. This article represents views of the authors, and does not necessarily represent the views of the Global Catastrophic Risk Institute.

Open Access This article is distributed under the terms of the Creative Commons Attribution 4.0 International License (http://crea tivecommons.org/licenses/by/4.0/), which permits unrestricted use, distribution, and reproduction in any medium, provided you give appropriate credit to the original author(s) and the source, provide a link to the Creative Commons license, and indicate if changes were made.

\section{References}

Aizen, M.A., L.A. Garibaldi, S.A. Cunningham, and A.M. Klein. 2009. How much does agriculture depend on pollinators? Lessons from long-term trends in crop production. Annals of Botany 103(9): 1579-1588.

Bailey, R., T.G. Benton, A. Challinor, J. Elliott, D. Gustafson, B. Hiller, A. Jones, A. Kent, K. Lewis, T. Meacham, M. Rivington, R. Tiffin, and D. Wuebbles. 2015. Extreme weather and resilience of the global food system: Final project report from the UK-US taskforce on extreme weather and global food system resilience. UK: The Global Food Security Programme.

Barrett, A.M., S.D. Baum, and K.R. Hostetler. 2013. Analyzing and reducing the risks of inadvertent nuclear war between the United States and Russia. Science \& Global Security 21(2): 106-133.

Baum, S.D., D.C. Denkenberger, and J.M. Pearce. 2016. Alternative foods as a solution to global food supply catastrophes. Solutions 7(4): 31-35.

Baum, S.D, D.C. Denkenberger, J.M. Pearce, A. Robock, and R. Winkler. 2015. Resilience to global food supply catastrophes. Environment Systems and Decisions 35(2): 301-313.

Beckstead, N. 2013. On the overwhelming importance of shaping the far future. Doctoral thesis. New Brunswick, NJ: Rutgers University.

Bolstad, W.M. 2013. Introduction to bayesian statistics. Hoboken, NJ: John Wiley \& Sons.

Chrisman, L., M. Henrion, R. Morgan, B. Arnold, F. Brunton, A. Esztergar, and J. Harlan. 2007. Analytica user guide. Los Gatos, CA: Lumina Decision Systems.

Denkenberger, D.C., and J.M. Pearce. 2014. Feeding everyone no matter what: Managing food security after global catastrophe. London: Academic Press.

Denkenberger, D.C., and J.M. Pearce. 2015. Feeding everyone: Solving the food crisis in event of global catastrophes that kill crops or obscure the sun. Futures 72 (September): 57-68.

Do, T., K. Anderson, and B.W. Brorsen. 2010. The world's wheat supply. Stillwater, OK: Oklahoma Cooperative Extension Service.

Earth Policy Institute. 2011. Rising meat consumption takes big bite out of grain harvest. New Brunswick, NJ: Earth Policy Institute, Rutgers University.

Ehrlich, P.R., and A.H. Ehrlich. 2013. Can a collapse of global civilization be avoided? Proceedings of the Royal Society B 280: 20122845. doi:10.1098/rspb.2012.2845.

Foley, J.A., N. Ramankutty, K.A. Brauman, E.S. Cassidy, J.S. Gerber, M. Johnston, N.D. Mueller, et al. 2011. Solutions for a cultivated planet. Nature 478(7369): 337-342.

FAO (Food and Agriculture Organization). 2005. Biological diversity. Global forest resources assessment 2005. Progress towards sustainable forest management. http://www.fao.org/docrep/008/ a0400e/a0400e00.htm. Accessed 21 Aug 2016.
FAO (Food and Agriculture Organization). 2015. The state of food insecurity in the world. Meeting the 2015 international hunger targets: Taking stock of uneven progress. Rome, Italy: Food and Agriculture Organization of the United Nations. http://www.fao.org/3/a-i4646e/index.html. Accessed 21 Aug 2016.

GiveWell. 2015a. Against Malaria Foundation (AMF). http://www.givewell.org/international/top-charities/amf. Accessed Jul 2015.

GiveWell. 2015b. Your dollar goes further overseas. Giving 101: The basics. http://www.givewell.org/giving101/Your-dollar-goesfurther-overseas. Accessed Jul 2015.

Godfray, H.C.J., J.R. Beddington, I.R. Crute, L. Haddad, D. Lawrence, J.F. Muir, J. Pretty, S. Robinson, S.M. Thomas, and C. Toulmin. 2010. Food security: The challenge of feeding 9 billion people. Science 327(5967): 812-818.

Goodhand, J. 2003. Enduring disorder and persistent poverty: A review of the linkages between war and chronic poverty. World Development 31(3): 629-646.

Gwatkin, D.R. 1980. How many die? A set of demographic estimates of the annual number of infant and child deaths in the world. American Journal of Public Health 70(12): 1286-1289.

Helfand, I. 2013. Nuclear famine: Two billion people at risk, 2nd edn. International Physicians for the Prevention of Nuclear War. https://www.mapw.org.au/files/downloads/two-billion-atrisk.pdf. Accessed 21 Aug 2016.

Henneberg, M. 1998. Evolution of the human brain: Is bigger better? Clinical and Experimental Pharmacology and Physiology 25(9): 745-749.

Keller, E.J. 1992. Drought, war, and the politics of famine in Ethiopia and Eritrea. The Journal of Modern African Studies 30(4): 609-624.

Keramat, M., and R. Kielbasa. 1997. Latin hypercube sampling Monte Carlo estimation of average quality index for integrated circuits. In Analog design issues in digital VLSI circuits and systems, ed. J.J. Becerra, E.G. Friedman, 131-142. New York: Springer.

Kim, K.-Y., and H.-J. Chung. 2000. Flavor compounds of pine sprout tea and pine needle tea. Journal of Agriculture and Food Chemistry 48(4): 1269-1272.

Langan, P., S. Gnanakaran, K.D. Rector, N. Pawley, D.T. Fox, D.W. Cho, and K.E. Hammel. 2011. Exploring new strategies for cellulosic biofuels production. Energy \& Environmental Science 4: 3820-3833.

Lazzaro, J. 2013. Bengal famine of 1943-A man-made holocaust. International Business Times, 22 February 2013.

Loftas, T., and J. Ross. 1995. Dimensions of need: An atlas of food and agriculture. Rome, Italy: Food and Agriculture Organization of the United Nations.

Mason, B., D. Pyle, and C. Oppenheimer. 2004. The size and frequency of the largest explosive eruptions on earth. Bulletin of Volcanology 66(8): 735-748.

Meadows, D.H., J. Randers, and D.L. Meadows. 2004. Limits to growth: The 30 year update. White River Junction, VT: Chelsea Green Publishing Company.

Miller, T.R. 2000. Variations between countries in values of statistical life. Journal of Transport Economics and Policy 34(2): 169-188.

Morgan, M.G., and M. Henrion. 1990. Uncertainty: A guide to dealing with uncertainty in quantitative risk and policy analysis. New York: Cambridge University Press.

Myers, R.H., D.C. Montgomery, and C.M. Anderson-Cook. 2009. Response surface methodology: Process and product optimization using designed experiments, 3rd edn. Hoboken, NJ: John Wiley \& Sons.

Napier, W. 2008. Hazards from comets and asteroids. In Global catastrophic risks, ed. N. Bostrom and M.M. Cirkovic, 222-237. New York: Oxford University Press. 
Oerke, E.C. 2006. Crop losses to pests. The Journal of Agriculture Science 144(1): 31-43.

Özdoğan, M., A. Robock, and C.J. Kucharik. 2013. Impacts of a nuclear war in South Asia on soybean and maize production in the Midwest United States. Climatic Change 116(2): 373-387.

Pearce, J.M., D. Denkenberger, and H. Zielonka. 2009. Accelerating applied sustainability by utilizing return on investment for energy conservation measures. International Journal of Energy, Environment and Economics 17(1): 61-80.

Rampino, M.R. 2008. Super-volcanism and other geophysical processes of catastrophic import. In Global catastrophic risks, ed. N. Bostrom and M.M. Cirkovic, 205-221. New York: Oxford University Press.

Robinson, L.A. 2007. How US government agencies value mortality risk reductions. Review of Environmental Economics and Policy 1(2): 283-299.

Rosen, J. 2016. Thinking the unthinkable. Science 353(6296): 232-237.
Spinosa, R. 2008. Fungi and sustainability. Fungi 1(1): 38-43.

Turco, R.P., O.B. Toon, T.P. Ackerman, I.B. Pollack, and C. Sagan 1990. Climate and smoke: An appraisal of nuclear winter. Science 247: 166-176.

Unibio. 2014. What is uniprotein ${ }^{\circledR}$ ? http://www.unibio.dk/?page_id=47. Accessed Jul 2015.

UNICEF (United Nations Children's Emergency Fund). 2006. The state of the world's children. United Nations Children's Fund, New York.

Valdes, P. 2011. Built for stability. Nature Geoscience 4(7): 414-416.

Von Braun, J., T. Teklu, and P. Webb. 1999. Famine in Africa: Causes, responses, and prevention. Washington, DC: International Food Policy Research Institute.

Waldman, R.J. 2001. Public health in times of war and famine: What can be done? What should be done? JAMA The Journal of the American Medical Association 286(5): 588-590. 